
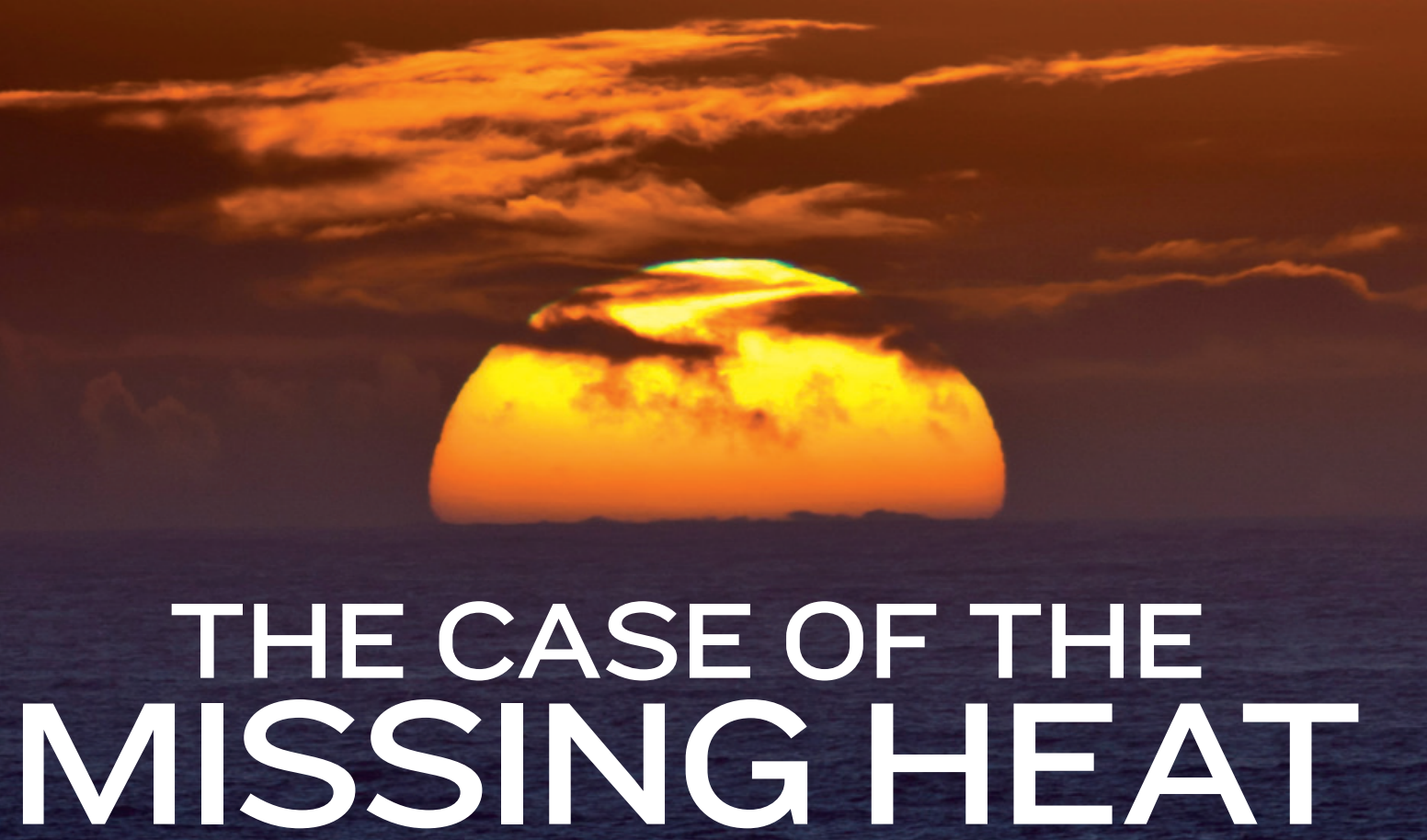

Sixteen years into the mysterious 'global-warming hiatus',
scientists are piecing together an explanation.

BY JEFF TOLLEFSON

$T$

he biggest mystery in climate science today may have begun, unbeknownst to anybody at the time, with a subtle weakening of the tropical trade winds blowing across the Pacific Ocean in late 1997. These winds normally push sun-baked water towards Indonesia. When they slackened, the warm water sloshed back towards South America, resulting in a spectacular example of a phenomenon known as El Niño. Average global temperatures hit a record high in 1998 - and then the warming stalled.

For several years, scientists wrote off the stall as noise in the climate system: the natural variations in the atmosphere, oceans and biosphere that drive warm or cool spells around the globe. But the pause has persisted, sparking a minor crisis of confidence in the field. Although there have been jumps and dips, average atmospheric temperatures have risen little since 1998, in seeming defiance of projections of climate models and the ever-increasing emissions of greenhouse gases. Climate sceptics have seized on the temperature trends as evidence that global warming 
has ground to a halt. Climate scientists, meanwhile, know that heat must still be building up somewhere in the climate system, but they have struggled to explain where it is going, if not into the atmosphere. Some have begun to wonder whether there is something amiss in their models.

Now, as the global-warming hiatus enters its sixteenth year, scientists are at last making headway in the case of the missing heat. Some have pointed to the Sun, volcanoes and even pollution from China as potential culprits, but recent studies suggest that the oceans are key to explaining the anomaly. The latest suspect is the El Niño of 1997-98, which pumped prodigious quantities of heat out of the oceans and into the atmosphere - perhaps enough to tip the equatorial Pacific into a prolonged cold state that has suppressed global temperatures ever since.

“The 1997 to '98 El Niño event was a trigger for the changes in the Pacific, and I think that's very probably the beginning of the hiatus," says Kevin Trenberth, a climate scientist at the National Center for Atmospheric Research (NCAR) in Boulder, Colorado. According to this theory, the tropical Pacific should snap out of its prolonged cold spell in the coming years. "Eventually," Trenberth says, "it will switch back in the other direction."

\section{STARK CONTRAST}

On a chart of global atmospheric temperatures, the hiatus stands in stark contrast to the rapid warming of the two decades that preceded it. Simulations conducted in advance of the 2013-14 assessment from the Intergovernmental Panel on Climate Change (IPCC) suggest that the warming should have continued at an average rate of $0.21^{\circ} \mathrm{C}$ per decade from 1998 to 2012 . Instead, the observed warming during that period was just $0.04^{\circ} \mathrm{C}$ per decade, as measured by the UK Met Office in Exeter and the Climatic Research Unit at the University of East Anglia in Norwich, UK.

The simplest explanation for both the hiatus and the discrepancy in the models is natural variability. Much like the swings between warm and cold in day-to-day weather, chaotic climate fluctuations can knock global temperatures up or down from year to year and decade to decade. Records of past climate show some long-lasting global heatwaves and cold snaps, and climate models suggest that either of these can occur as the world warms under the influence of greenhouse gases.

But none of the climate simulations carried out for the IPCC produced this particular hiatus at this particular time. That has led sceptics - and some scientists - to the controversial conclusion that the models might be overestimating the effect of greenhouse gases, and that future warming might not be as strong as is feared. Others say that this conclusion goes against the long-term temperature trends, as well as palaeoclimate data that are used to extend the temperature record far into the past. And many researchers caution against evaluating models on the basis of a relatively short-term blip in the climate. "If you are interested in global climate change, your main focus ought to be on timescales of 50 to 100 years," says Susan Solomon, a climate scientist at the Massachusetts Institute of Technology in Cambridge.

But even those scientists who remain confident in the underlying models acknowledge that there is increasing pressure to work out just what is happening today. "A few years ago you saw the hiatus, but it could be dismissed because it was well within the noise," says Gabriel Vecchi, a climate scientist at the US National Oceanic and Atmospheric Administration's Geophysical Fluid Dynamics Laboratory in Princeton, New Jersey. "Now it's something to explain."
Researchers have followed various leads in recent years, focusing mainly on a trio of factors: the Sun ${ }^{1}$, atmospheric aerosol particles ${ }^{2}$ and the oceans ${ }^{3}$. The output of energy from the Sun tends to wax and wane on an 11-year cycle, but the Sun entered a prolonged lull around the turn of the millennium. The natural 11-year cycle is currently approaching its peak, but thus far it has been the weakest solar maximum in a century. This could help to explain both the hiatus and the discrepancy in the model simulations, which include a higher solar output than Earth has experienced since 2000 .

An unexpected increase in the number of stratospheric aerosol particles could be another factor keeping Earth cooler than predicted. These particles reflect sunlight back into space, and scientists suspect that small volcanoes - and perhaps even industrialization in China - could have pumped extra aerosols into the stratosphere during the past 16 years, depressing global temperatures.

Some have argued that these two factors could be primary drivers of the hiatus, but studies published in the past few years suggest that their effects are likely to be relatively small $^{4,5}$. Trenberth, for example, analysed their impacts on the basis of satellite measurements of energy entering and exiting the planet, and estimated that aerosols and solar activity account for just $20 \%$ of the hiatus. That leaves the bulk of the hiatus to the oceans, which serve as giant sponges for heat. And here, the spotlight falls on the equatorial Pacific.

\section{BLOWING HOT AND COLD}

Just before the hiatus took hold, that region had turned unusually warm during the El Niño of 1997-98, which fuelled extreme weather across the planet, from floods in Chile and California to droughts and wildfires in Mexico and Indonesia. But it ended just as quickly as it had begun, and by late 1998 cold waters - a mark of El Niño's sister effect, La Niña - had returned to the eastern equatorial Pacific with a vengeance. More importantly, the entire eastern Pacific flipped into a cool state that has continued more or less to this day.

This variation in ocean temperature, known as the Pacific Decadal Oscillation (PDO), may be a crucial piece of the hiatus puzzle. The cycle reverses every 15-30 years, and in its positive phase, the oscillation favours El Niño, which tends to warm the atmosphere (see 'The fickle ocean'). After a couple of decades of releasing heat from the eastern and central Pacific, the region cools and enters the negative phase of the PDO. This state tends towards La Niña, which brings cool waters up from the depths along the Equator and tends to cool the planet. Researchers identified the PDO pattern in 1997, but have only recently begun to understand how it fits in with broader ocean-circulation patterns and how it may help to explain the hiatus.

One important finding came in 2011, when a team of researchers at NCAR led by Gerald Meehl reported that inserting a PDO pattern into global climate models causes decade-scale breaks in global warming ${ }^{3}$. Ocean-temperature data from the recent hiatus reveal why: in a subsequent study, the NCAR researchers showed that more heat moved into the deep ocean after 1998, which helped to prevent the atmosphere from warming ${ }^{6}$. In a third paper, the group used computer models to document the flip side of the process: when the PDO switches to its positive phase, it heats up the surface ocean and atmosphere, helping to drive decades of rapid warming ${ }^{7}$.

A key breakthrough came last year from Shang-Ping Xie and Yu Kosaka at the Scripps Institution of Oceanography in La Jolla, 
THE PACIFIC'S GLOBAL REACH

As researchers have investigated why global temperatures have not risen much since 1998, many have focused on an ocean cycle known as the Pacific Decadal Oscillation (PDO). During periods when the PDO index is positive and the eastern Pacific is warm, global temperatures have risen quickly. During spells when the PDO index is negative, the warming has stagnated.

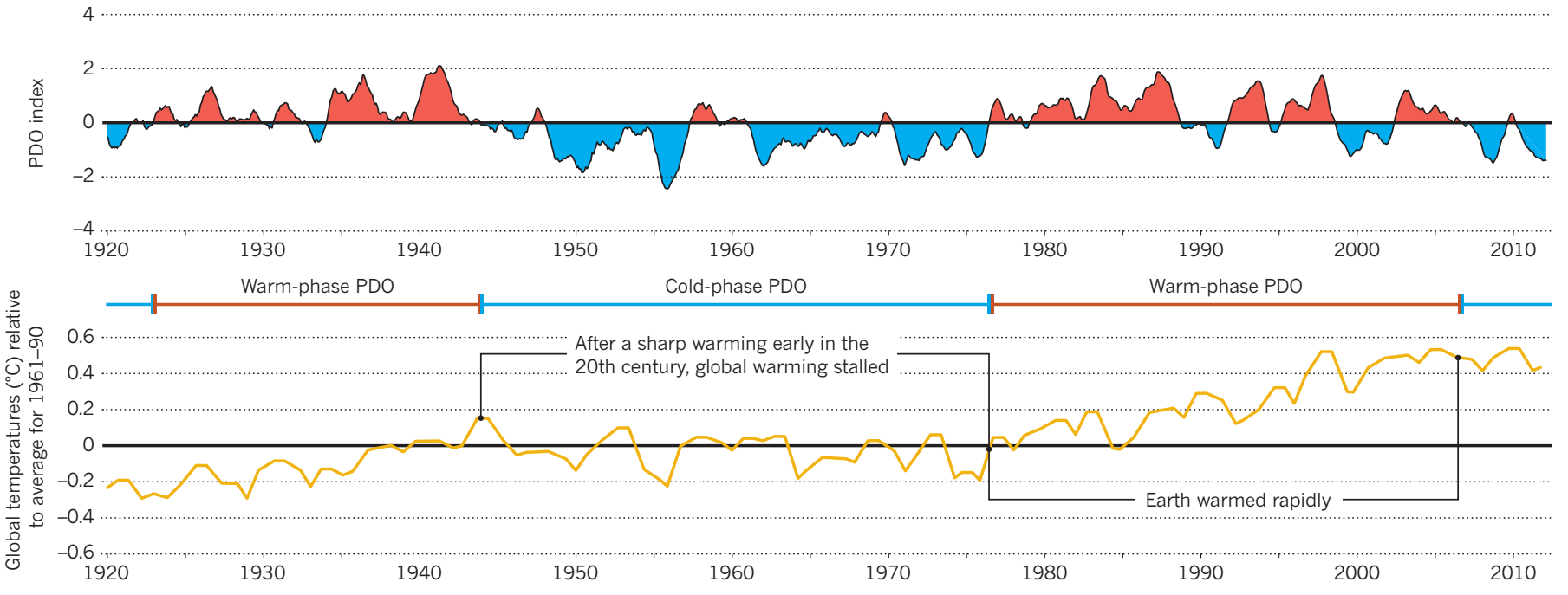

California. The duo took a different tack, by programming a model with actual sea surface temperatures from recent decades in the eastern equatorial Pacific, and then seeing what happened to the rest of the globe ${ }^{8}$. Their model not only recreated the hiatus in global temperatures, but also reproduced some of the seasonal and regional climate trends that have marked the hiatus, including warming in many areas and cooler northern winters.

"It was actually a revelation for me when I saw that paper," says John Fyfe, a climate modeller at the Canadian Centre for Climate Modelling and Analysis in Victoria. But it did not, he adds, explain everything. "What it skirted was the question of what is driving the tropical cooling."

That was investigated by Trenberth and John Fasullo, also at NCAR, who brought in winds and ocean data to explain how the pattern emerges ${ }^{4}$. Their study documents how tropical trade winds associated with La Niña conditions help to drive warm water westward and, ultimately, deep into the ocean, while promoting the upwelling of cool waters along the eastern equatorial region. In extreme cases, such as the La Niña of 1998, this may be able to push the ocean into a cool phase of the PDO. An analysis of historical data buttressed these conclusions, showing that the cool phase of the PDO coincided with a few decades of cooler temperatures after the Second World War (see 'The Pacific's global reach'), and that the warm phase lined up with the sharp spike seen in global temperatures between 1976 and 1998 (ref. 4).

"I believe the evidence is pretty clear," says Mark Cane, a climatologist at Columbia University in New York. "It's not about aerosols or stratospheric water vapour; it's about having had a decade of cooler temperatures in the eastern equatorial Pacific."

\section{HEATED DEBATE}

Cane was the first to predict the current cooling in the Pacific, although the implications weren't clear at the time. In 2004, he and his colleagues found that a simple regional climate model predicted a warm shift in the Pacific that began around 1976, when global temperatures began to rise sharply ${ }^{9}$. Almost as an afterthought, they concluded their paper with a simple forecast: "For what it is worth the model predicts that the 1998 El Niño ended the post-1976 tropical Pacific warm period."

It is an eerily accurate result, but the work remains hotly contested, in part because it is based on a partial climate model that focuses on the equatorial Pacific alone. Cane further maintains that the trend over the past century has been towards warmer temperatures in the western Pacific relative to those in the east. That opens the door, he says, to the possibility that warming from greenhouse gases is driving La Niña-like conditions and could continue to do so in the future, helping to suppress global warming. "If all of that is true, it's a negative feedback, and if we don't capture it in our models they will overstate the warming," he says.

There are two potential holes in his assessment. First, the historical ocean-temperature data are notoriously imprecise, leading many researchers to dispute Cane's assertion that the equatorial Pacific shifted towards a more La Niña-like state during the past century ${ }^{10}$. Second, many researchers have found the opposite pattern in simulations with full climate models, which factor in the suite of atmospheric and oceanic interactions beyond the equatorial Pacific. These tend to reveal a trend towards more El Niño-like conditions as a result of global warming. The difference seems to lie, in part, in how warming influences evaporation in areas of the Pacific, according to Trenberth. He says the models suggest that global warming has a greater impact on temperatures in the relatively cool east, because the increase in evaporation adds water vapour to the atmosphere there and enhances atmospheric warming; this effect is weaker in the warmer western Pacific, where the air is already saturated with moisture.

Scientists may get to test their theories soon enough. At present, strong tropical trade winds are pushing ever more warm water westward towards Indonesia, fuelling storms such as November's Typhoon Haiyan, and nudging up sea levels in the western Pacific; they are now roughly 20 centimetres higher than those in the eastern Pacific. Sooner or later, the trend will inevitably reverse. "You can't keep piling up warm water in the western Pacific," Trenberth says. "At some point, the water will get so high that it just sloshes back." And when that happens, if scientists are on the right track, the missing heat will reappear and temperatures will spike once again. - SEE EDITORIALP.261

Jeff Tollefson covers climate, energy and the environment for Nature.

1. Lean, J. L. \& Rind, D. H. Geophys. Res. Lett. 36, L15708 (2009).

2. Hansen, J., Sato, M., Kharecha, P. \& von Schuckmann, K. Atmos. Chem. Phys. 11, 13421-13449 (2011)

3. Meehl, G. A., Arblaster, J. M., Fasullo, J. T., Hu, A. \& Trenberth, K. E. Nature Clim Change 1, 360-364 (2011)

4. Trenberth, K. E. \& Fasullo, J. T. Earth's Future http://dx.doi. org/10.1002/2013EF000165 (2013).

5. Feulner, G. \& Rahmstorf, S. Geophys. Res. Lett. 37, L05707 (2010),

6. Balmaseda, M. A., Trenberth, K. E. \& Källén, E. Geophys. Res. Lett. 40, 1754-1759 (2013).

7. Meehl, G. A., Hu, A., Arblaster, J. M., Fasullo, J. \& Trenberth, K. E. J. Clim. 26, 7298-7310 (2013).

8. Kosaka, Y. \& Xie, S.-P. Nature 501, 403-407 (2013).

9. Seager, R. et al. in Earth's Climate: The Ocean-Atmosphere Interaction. Geophys. Monogr. Ser. 147, 105-120 (2004).

10.DiNezio, P., Clement, A. \& Vecchi, G. A. Eos 91, 141-152 (2010). 